\section{Lohnt sich das?}

- Ein paar Wochen vor dem diesjährigen physiokongress (๑ S. 52) fragte mich eine Freundin, auch Physio, ob ich meine, dass sich der Besuch des Kongresses lohnen würde. „Ist ja schon recht teuer - 90 Euro für einen Tag. “Sie schob hinterher: „Dafür könnte ich ja auch eine Fortbildung machen.“

_ Ich musste nicht lange nachdenken. „Das lohnt sich definitiv“, sagte ich. „Bei einer Fortbildung bekommst du an einem Tag ein Update von einem Referenten zu einem Thema. Bei uns bekommst du an einem Tag Updates von 15 Referenten zu sechs unterschiedlichen Themengebieten. Bei der Fobi triffst du vielleicht 20, 30 andere Therapeuten. Bei uns sind

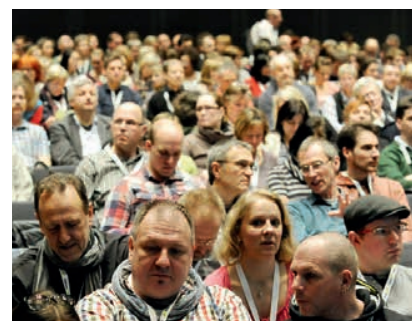
Lohnt sich. Auf Kongressen gibt es geballte Information und hunderte von Kollegen auf einmal.

es mehrere Hundert. Zudem kannst du dich

auf der Messe TheraPro ausgiebig darüber informieren, was es auf dem Physiomarkt Neues gibt. Stell dir vor, der Referent auf der Fobi taugt nichts. Beim Kongress kannst du bei einer „Niete“ einfach auf die Messe gehen und die „verlorene“ Zeit sinnvoll nutzen.

_ Meine Freundin kam dann tatsächlich auf den physiokongress - und fuhr am Abend zufrieden und bis obenhin upgedated nach Hause. Ein paar Tage später rief sie mich an: „Du, da ist demnächst wieder so ein Kongress. Gehst du da auch hin ...?“

Herzlichst, Ihr
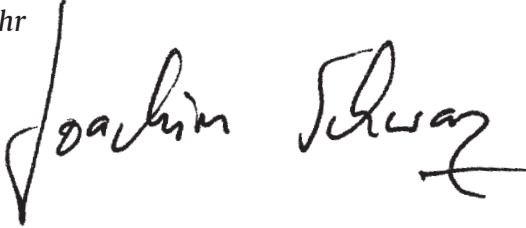

PS: Die nächste Chance zum Mega-Update auf dem physiokongress ist vom 30. Januar bis 1. Februar 2015. Und für „zwischendurch“ haben wir am 5. April 2014 den Physiotag auf der FIBOmed.
Und das gibt es in dieser Ausgabe zu gewinnen:

Bücher

3 mal „Persönlichkeit, Entscheidung und Verhalten“" Seite 10

1 mal „Anatomie und Biomechanik der Hand“ S Seite 36

und außerdem

1 Boulderset 